\title{
ANALISIS KEBIJAKAN PEMERINTAH DAERAH \\ DALAM MENDUKUNG TINGKAT KEBERLANJUTAN SUMBER DAYA PERIKANAN (Studi Kasus di Kawasan Pangandaran, Kabupaten Ciamis)
}

\author{
Atikah Nurhayati \\ Fakultas Perikanan dan Ilmu Kelautan Universitas Padjadjaran \\ Email: atikah.nurhayati@unpad.ac.id
}

Diterima 6 September 2012 - Disetujui 23 November 2012

\begin{abstract}
ABSTRAK
Penelitian ini bertujuan untuk mengkaji sejauh mana kebijakan pemerintah daerah dalam mendukung tingkat keberlanjutan pengelolaan sumber daya perikanan melalui pendekatan model sinergitas perilaku ekonomi nelayan (Suatu Kasus di Kawasan Pangandaran Kabupaten Ciamis Provinsi Jawa Barat). Analisis terhadap kebijakan pemerintah daerah dalam mendukung tingkat keberlanjutan pengelolaan sumber daya perikanan tangkap dilakukan dengan menggunakan Analytical Hierarkhi Process (AHP). Kebijakan pemerintah daerah dalam mendukung tingkat keberlanjutan pengelolaan sumber daya perikanan melalui alternatif kebijakan Co-Management berpengaruh sebesar $44,6 \%$ terhadap tingkat keberlanjutan pengelolaan sumber daya perikanan. Pengendalian upaya penangkapan memiliki nilai bobot 0,336 artinya kebijakan pemerintah melalui pengendalian upaya penangkapan memiliki pengaruh sebesar $33,6 \%$ terhadap tingkat keberlanjutan pengelolaan sumber daya perikanan. Sinergitas perilaku ekonomi nelayan memiliki nilai bobot 0,131 artinya kebijakan pemerintah dengan memperhatikan sinergitas perilaku ekonomi nelayan memiliki pengaruh sebesar 13,1\% terhadap tingkat keberlanjutan pengelolaan sumber daya perikanan. Penegakan hukum dan kelembagaan memiliki nilai bobot 0,088 artinya setiap kebijakan pemerintah melalui penegakan hukum dan kelembagaan memiliki pengaruh sebesar $0,88 \%$ terhadap tingkat keberlanjutan pengelolaan sumber daya perikanan. Kebijakan Co-management memiliki pengaruh yang besar terhadap tingkat keberlanjutan sumber daya perikanan tangkap di Kawasan Pangandaran Provinsi Jawa Barat.
\end{abstract}

Kata Kunci: kebijakan, nelayan, sinergitas perilaku ekonomi

\section{Abstract: Analysis of the Local Government Policy Supporting to Sustainable Fisheries Resources (Case Study in the Pangandaran, Ciamis District). By: Atikah Nurhayati.}

This research aims to examine extent of government policy in support of Ciamis district level management sustainability of fishery resources through the synergy model approach to economic behaviour of fishers. Analysis of government policy in supporting the sustainability of fisheries resource management wes using the Analytical Hierarchy Process (AHP). Local government policies in supporting the sustainability of fisheries resource management were given through alternatives policies Co-Management, control of fishing effort, synergy model of economic behaviour of fishers, law enforcement and institutional. Government policy in supporting sustainable fisheries resource management through policy alternatives Co-Management influence for $44.6 \%$ of the level of sustainability of fisheries resources management. Controlling fishing effort has a value of 0.336 means that partial weight alternative government policy by controlling fishing effort has the effect of $33.6 \%$ of the level of sustainability of fisheries resource management; synergy of economic behaviour fishers has a value of 0.131 means that partial weight alternative government policies with respect to economic behaviour of fishers have synergy effect of 
$13.1 \%$ of the level of sustainability of fisheries resource management of law enforcement and institutions have partial weight value of 0.088 means that every government policy through the enforcement of laws and institutions have an influence on the level of $0.88 \%$ sustainable management of fisheries resources. Co-management policy has a great influence on the level of sustainability of fisheries resources in the area of Pangandaran, West Java Province.

\section{Keywords: policy, fishermen, synergy of economic behavior}

\section{PENDAHULUAN}

Pengelolaan sumber daya perikanan tangkap dengan memadukan berbagai faktor yang saling terkait dan berpengaruh terhadap kelangsungan sumberdaya perikanan menjadi dasar dalam penentuan kebijakan pemerintah. Permintaan komoditas perikanan untuk pemenuhan kebutuhan manusia dan sinergitas nelayan dalam memanfaatkan sumber daya perikanan tangkap tidak terlepas dari nilai ekonomi. Kegiatan ekonomi di wilayah pesisir pada umumnya melibatkan lebih dari satu sektor, termasuk di dalamnya sektor perikanan maupun sektor pariwisata bahari. Akibat padatnya kegiatan ekonomi yang ada, banyak wilayah di Indonesia mengalami kerusakan lingkungan cukup parah sehingga terancam keberlanjutannya. Bentuk kerusakannya seperti : sedimentasi, kerusakan terumbu karang, kerusakan hutan mangrove dan abrasi pantai adalah beberapa bentuk kerusakan alam yang umum terjadi di wilayah pesisir.

Pengelolaan sumber daya perikanan adalah suatu proses yang terintegrasi mulai dari pengumpulan informasi, analisis, perencanaan, konsultasi, pengambilan keputusan, alokasi sumber dan implementasinya, dalam rangka menjamin kelangsungan produktivitas serta pencapaian tujuan pengelolaan. Menurut FAO dalam Pomeroy et al., 2009 "managing fisheries in a manner that addresses multiple needs and desires of society, without jeopar- dizing options for future generations, to benefit from the full- range of goods and services provided by marine ecosystems". Lackey (1998) Fisheries management has been defined as "the practice of analyzing and selecting options to maintain or alter the structure, dynamics, and interaction of habitat, aquatic biota, and man to achieve human goals and objectives". Pada definisi tersebut pada prinsipnya pengelolaan sumber daya perikanan bertujuan untuk memenuhi kebutuhan manusia tanpa merusak sumber daya perikanan tersebut untuk generasi yang akan datang.

Fauzi (2005) mengemukakan bahwa pengelolaan sumber daya ikan adalah bagaimana memanfaatkan sumber daya tersebut sehingga menghasilkan manfaat ekonomi yang tinggi bagi pengguna namun kelestariannya tetap terjaga. Dalam pengelolaan sumber daya perikanan dilakukan melalui pendekatan bio-ekonomi yang mengandung makna ekonomi dan makna konservasi atau biologi. Menurut Rudel dalam Edwar et al., (2001) 'parametric management' from fisheries around the world and suggested that many 'traditional' management systems that had successfully sustained fisheries were based on such parametric controls, which include protection of spawning and nursery areas, limited access, closed seasons and size limits. These management measures are often based on local or indigenous knowledge. Definisi tersebut mengandung pengertian bahwa parameter dari pengelolaan perikanan di seluruh dunia menyarankan bahwa banyak sistem manajemen tradisional yang telah berhasil mempertahankan perikanan didasarkan pada kontrol parameter, yang meliputi perlindungan daerah pemijahan dan pembibitan, akses terbatas, menutup musim dan batas ukuran hasil tangkapan. Langkah-langkah manajemen tersebut sering didasarkan pada pengetahuan lokal atau adat masyarakat setempat. 
Pantai Bojongsalawe Kecamatan Parigi Kabupaten Ciamis yang menjadi salah satu lokasi penelitian adalah salah satu contoh akibat eksploitasi sumber daya yang tidak terkontrol dan pernah mengalami abrasi pantai penyebabnya adalah ombak yang besar di Pantai Selatan Jawa yang mengakibatkan abrasi kurang lebih sepanjang 600 meter (Dinas Kelautan dan Perikanan Kab. Ciamis, 2007). Dampak dari kerusakan tersebut diperparah dengan berbagai bentuk kejadian alam. Salah satu contohnya adalah gempa yang diikuti dengan tsunami yang terjadi di banyak wilayah pesisir Indonesia termasuk Kawasan Pangandaran yang juga menjadi lokasi utama penelitian ini.

Gempa dan tsunami yang terjadi pada tanggal 17 Juli 2006 telah menghancurkan sebagian besar infrastruktur dan berbagai sarana milik nelayan termasuk perahu dan peralatan tangkap. Bencana yang merusak aset ekonomi di wilayah pesisir seperti itu, apabila tidak ditanggani dengan baik dan menyeluruh dapat berdampak lanjut pada sikap dan tindakan para pelaku ekonomi terhadap sumber daya. Berdasarkan latar belakang di atas dapat dirumuskan masalah yaitu sejauhmana kebijakan pemerintah daerah dalam mendukung tingkat keberlanjutan pengelolaan sumberdaya perikanan. Penelitian ini bertujuan untuk menganalisis kebijakan pemerintah daerah dalam mendukung tingkat keberlanjutan pengelolaan sumber daya perikanan tangkap melalui model sinergitas perilaku ekonomi nelayan.

\section{METODOLOGI}

\section{Kerangka Teoritis}

Conway dalam Edwar, et al., 2001. Sustainability is defined as "the ability of a system to maintain productivity in spite of a major disturbance, such as is caused by intensive stress or a large perturbation", (Keberlanjutan didefinisikan sebagai kemampuan suatu sistem dalam mempertahankan produktivitas meskipun terjadi gangguan besar, seperti yang disebabkan oleh stres yang intensif atau perturbasi besar). Mohotola et al., (2009) mengemukakan bahwa keberlanjutan sangat tergantung pada sejumlah faktor sosial, ekonomi, kelembagaan, dan teknologi yang mencakup: (1) ukuran besar kecilnya kelompok pengguna, (2) kedekatan pengguna dengan sumber daya; (3) homogenitas antara anggota kelompok, (4) mekanisme penegakan yang efektif; (5) pengalaman masa lalu organisasi; (6) dukungan eksternal, dan (7) kepemimpinan yang kuat.

Model pengelolaan yang berbasis masyarakat memberikan beberapa keuntungan dan kerugian (Bengen, 2005) yaitu sebagai berikut :

Keuntungan Community Based Management sumber daya perikanan yaitu:

1. Mampu mendorong pemerataan (equity) dalam pengelolaan sumberdaya ikan;

2. Mampu merefleksikan kebutuhan masyarakat lokal yang spesifik;

3. Mampu meningkatkan manfaat lokal bagi seluruh anggota masyarakat yang ada;

4. Mampu meningkatkan efisiensi secara ekologis dan ekonomis;

5. Responsif dan adaptif terhadap variasi kondisi sosial dan lingkungan lokal;

6. Masyarakat lokal termotivasi untuk mengelola sumber daya secara berkelanjutan.

Kelemahan Community Based Management sumberdaya perikanan yaitu:

1. Hanya dapat diterapkan dengan baik pada masyarakat yang kondisi strukturnya masih sederhana dengan skala dan wilayah kegiatan yng tidak luas;

2. Tingkat pendidikan dan kesadaran masyarakat tentang pentingnya lingkungan;

3. Terjadinya kesukaran dalam implementasi karena kurang mendapat dukungan;

4. Hanya efektif pada kawasan pengelolaan 
yang batas geografisnya jelas dan terbatas;

5. Rentan terhadap intervensi luar atau peledakan permintaan sumber daya ikan dan jasa lingkungan.

Ada beberapa pengertian mengenai co-management yaitu sebagai berikut : Co-management is defined as the sharing of responsibilities between governmental institutions and groups of resource users (Persoon et al., dalam Matsuda et al., 2009). Co-management is adaptive, where ecological knowledge and institutional arrangements are tested and revised in a dynamic,on going, self-organised process of learning-by-doing (Mc-Conney \& Baldeo, 2007). Definitions of co-management centre on the theme of sharing management responsibility and authority between the state and other stakeholders (Mc-Conney, 1998; Brown and Pomeroy, 1999; Pomeroy, et al., 2001. Co-management encompasses a range of institutional arrangements often depicted as a scale based on the relative proportions of responsibility and authority shared between state and stakeholders. (McConney \& Baldeo,2007).

Berbagai definisi mengenai pengertian Co-management dapat disimpulkan bahwa Co-management merupakan pembagian tanggung jawab dan kewenangan antara pemerintah dengan masyarakat sebagai stakeholder dalam mengelola sumber daya alam yang merupakan milik bersama. Carter (1996) Community - Based Resources Management : "A strategy for achieving a people-centered development where the focus of decision making regard to the sustainable use of natural resources in area lies with the people in the communities of that area" (Suatu strategi untuk mencapai pembangunan yang berpusat pada manusia, pengambilan keputusan tentang keberlanjutan sumber daya dalam pemanfaatannya di daerah tersebut berada di tangan masyarakat).

Beberapa pola seperti Community Based Resource Management (CBRM) dan
Co-Management yang dikembangkan dari model tradisional (kearifan lokal seperti hak ulayat) telah banyak diacu untuk mengembangkan pola pengelolaan sumber daya yang bersifat partisipatif. Co-management is defined as the sharing of responsibilities between governmental institutions and groups of resource users (Persoon et al., dalam Matsuda, 2009). Co-management involves various degrees of delegation of management responsibility and authority between the local level (resources user/community) and the state level (national, provincial/state, municipal). Co management is midlle course between stage level concers in fisheries management for efficiency and equity and local level concerns for self governance, self regulation and active participation. Co management can serve as a mechanism for both fisheries management and for community and economic development by promoting participation of fisheries and the community in actively solving problem and addresing need. (Pomeroy, 1995). Dari pengertian Co-manajemen yang melibatkan berbagai tingkat pendelegasian tanggung jawab manajemen dan kewenangan antara tingkat lokal (masyarakat sebagai pengguna) dan tingkat negara (nasional, provinsi / kota). Co Manajemen dalam tahap pengelolaan perikanan bertujuan untuk efisiensi dan equity serta kepedulian tingkat lokal baik pemerintah dan partisipasi aktif dari masyarakat. Co Manajemen dapat berfungsi sebagai mekanisme untuk pengelolaan perikanan dan masyarakat serta pembangunan ekonomi dengan mempromosikan perikanan melalui partisipasi aktif masyarakat dalam memecahkan masalah guna memenuhi kebutuhan hidupnya.

\section{METODOLOGI}

\section{Lokasi dan Waktu Penelitian}

Metode yang digunakan dalam penelitian ini adalah metode survei. Menurut Nazir (2003), metode survei adalah pengamatan atau penyelidikan yang kritis untuk mendapatkan keterangan yang baik, terhadap suatu persoalan tertentu di dalam daerah atau lokasi tertentu. 
Penelitian ini dilaksanakan di Kawasan Pangandaran Kabupaten Ciamis Propinsi Jawa Barat pada bulan Agustus - Desember 2010.

\section{Sumber dan Tehnik Penggumpulan Data}

Data diambil dari data primer dan data sekunder. Data primer diperoleh dengan wawancara atau interview dan pemberian daftar pertanyaan kepada responden yang meliputi: tokoh masyarakat dan nelayan pemilik sebanyak 93 orang, anak buah kapal (ABK) sebanyak 93 orang, 4 orang aparat Dinas Perikanan dan Kelautan Kabupaten Ciamis dan 1 orang pegawai Badan Perencanaan Daerah Kabupaten Ciamis. Data sekunder diperoleh dari laporan-laporan tahunan tertulis lembaga atau instansi yang terkait dalam penelitian ini.

\section{Alat Analisis Hierarchy Process (AHP)}

Analisis data dilakukan dengan Analisis Hierarchy Process (AHP), karena AHP merupakan salah satu alat analisis yang dapat digunakan untuk kondisi ketidakpastian dan ketidaksempurnaan informasi dan beraga mnya kriteria suatu pengambilan keputusan (Saaty, 1993). Proses analisis dengan AHP dilakukan dengan melakukan perbandingan berpasangan (pairwise comparions) untuk mendapatkan tingkat kepentingan (importance) suatu kriteria relatif terhadap kriteria lain dan dapat dinyatakan dengan jelas. Proses perbandingan berpasangan ini dilakukan untuk setiap level/tingkat; tingkat 1 (tujuan umum), tingkat 2 (kriteria), tingkat 3 (sub kriteria), tingkat 4 (alternatif kegiatan). Proses analisis AHP ini dilakukan dengan perangkat lunak Expert Choise versi 9.0.

Analitical Hirarchy Process (AHP) merupakan proses berpikir yang terorganisir untuk permasalahan yang kompleks, rumit, dan tidak terstruktur yang memungkinkan adanya interaksi antar faktor, namun tetap memungkinkan untuk memikirkan faktor-faktor tersebut secara sederhana. AHP merupakan metode analisis pengambilan keputusan sederhana dan fleksibel yang menampung kreatifitas di dalam rancangannya terhadap suatu masalah. Adapun skala banding secara berpasangan, dapat dilihat pada Tabel 1.

Sebagaimana sebuah analisis multikriteria, AHP menurut Triantaphyllou dan Alfonso (1997) harus dilengkapi dengan analisis sensitivitas. Analisis sensitivitas ini digunakan untuk dapat melihat range (batasan) perubahan pendapat key person dalam pengambilan keputusan dengan AHP. Dengan analisis sensitivitas dapat dilihat komponen/elemen mana dari struktur hirarkhi yang paling sensitif terhadap perubahan bobotnya sehingga menghasilkan perubahan pada alternatif.

\section{PENGELOLAAN WILAYAH PESISIR DENGAN MELIBATKAN MASYARAKAT}

Berdasarkan hasil perhitungan dapat diketahui alternatif kebijakan yang harus dilakukan oleh pemerintah setempat pada dimensi ekologi, ekonomi, sosial, teknologi dan etik yaitu: Co-Management dengan memiliki nilai bobot parsial sebesar 0,446 artinya alaternatif kebijakan pemerintah melalui Co-Management akan memberikan pengaruh sebesar 44,6\% terhadap tingkat keberlanjutan pengelolaan sumberdaya perikanan.

Pengelolaan berbasis masyarakat di kawasan Pangandaran merupakan suatu sistem pengelolaan sumberdaya perikanan tangkap dimana masyarakat lokal terlibat secara aktif dalam proses pengelolaan sumber daya alam yang terkandung di dalamnya. Pola pengelolaan sumberdaya pesisir dan lautan telah mengalami pergeseran pada masa lalu dilakukan dalam pelaksanaannya masih bersifat top down, artinya semua kegiatan pengelolaan sumber daya pesisir dan lautan mulai dari membuat kebijakan, perencanaan, pelaksanaan, evaluasi dan monitoring dilakukan sepenuhnya oleh pemerintah tanpa melibatkan partisipasi masyarakat lokal, sekarang sudah melibatkan masyarakat lokal walaupun belum sepenuhnya. 
Tabel 1. Skala Banding Berpasangan.

Table 1. Pairwise Comparison Scale and Example.

\begin{tabular}{|c|c|c|}
\hline $\begin{array}{l}\text { Tingkat kepentingan/ } \\
\text { Comparison scale } \\
\text { Intensity }\end{array}$ & Definisi/Definition & Penjelasan/Explanation \\
\hline 1 & $\begin{array}{l}\text { Kedua elemen sama pentingnya / } \\
\text { Equal importance }\end{array}$ & $\begin{array}{l}\text { Dua elemen mempunyai pengaruh sama } \\
\text { besar terhadap tujuan / } \\
\text { Two factors contribute equally to the } \\
\text { objective }\end{array}$ \\
\hline 3 & $\begin{array}{l}\text { Elemen yang satu sedikit lebih } \\
\text { Penting dari elemen yang lain/ } \\
\text { Moderate importance of one over } \\
\text { another }\end{array}$ & $\begin{array}{l}\text { Pengalaman dan penilaian mendukung } \\
\text { salah satu faktor di atas yang lain / } \\
\text { Experience and judgment favor one } \\
\text { factor over another }\end{array}$ \\
\hline 5 & $\begin{array}{l}\text { Elemen yang satu lebih penting } \\
\text { dari eleman yang lain/ Essential } \\
\text { or strong importance }\end{array}$ & $\begin{array}{l}\text { Pengalaman dan penilaian sangat kuat } \\
\text { mendukung satu elemen dibanding } \\
\text { elemen yang lain/ } \\
\text { Experience and judgment strongly Favor } \\
\text { one factor over another. }\end{array}$ \\
\hline 7 & $\begin{array}{l}\text { Satu elemen jelas lebih penting } \\
\text { dari elemen yang lainnya/ } \\
\text { Very strong importance }\end{array}$ & $\begin{array}{l}\text { Sebuah elemen sangat disukai dan } \\
\text { menunjukkan dominasinya dalam } \\
\text { praktek } \\
\text { An elemen is strongly favored and its } \\
\text { dominance demonstrated in practice }\end{array}$ \\
\hline 9 & $\begin{array}{l}\text { Elemen yang ekstrim dan sangat } \\
\text { penting/ } \\
\text { Extreme importance }\end{array}$ & $\begin{array}{l}\text { Bukti mendukung salah satu faktor di } \\
\text { atas yang lain adalah urutan tertinggi } \\
\text { mungkin } \\
\text { The evidence of favoring one factor over } \\
\text { another is of the highest possible order } \\
\text { of affirmation }\end{array}$ \\
\hline & \multicolumn{2}{|c|}{$\begin{array}{l}\text { 2, 4, 6, } 8 \text { antara nilai tengah emelen yang berdekatan / } \\
\text { Intermediate values when compromise is needed }\end{array}$} \\
\hline
\end{tabular}

Strategi pengembangan masyarakat pesisir di kawasan Pangandaran Kabupaten Ciamis dilakukan melalui dua pendekatan yang bersifat struktural dan non struktural. Pendekatan struktural yaitu pendekatan makro yang menekankan pada penataan sistem dan struktur sosial politik. Pendekatan ini mengutamakan peranan instansi yang berwewenang atau organisasi yang dibentuk untuk pengelolaan wilayah pesisir. Dalam hal ini peranan masyarakat sangat penting tetapi akan kurang kuat karena aspek struktural biasanya lebih efektif bila dilakukan oleh pihak-pihak yang mempunyai kewenangan, paling tidak pada tahap awal seperti halnya pembuatan Pelabuhan Cikidang. Keberadaan pelabuhan perikanan sangat penting dalam menentukan produktivitas, efisiensi, dan keberlanjutan usaha perikanan tangkap.

Pembangunan Pelabuhan Cikidang yang belum selesai pada saat penelitian dilaksanakan, ternyata sudah memiliki sebagian fasilitas fungsional yang diperlukan seperti tempat pelelangan ikan, tempat pertemuan, fasilitas jalan, namun muara untuk tempat berlabuhnya kapal belum selesai dengan baik, seharusnya muara untuk tempat berlabuhnya kapal diselesaikan dulu baru fasilitas penunjang lainnya. Banyak ditemukan fasilitas penunjang yang sudah mulai rusak kembali, sedangkan muara tempat berlabuhnya kapal belum terselesaikan. Hal ini seharusnya menjadi perhatian bagi Pemerintah Daerah dan Pusat, ketika menentukan akan 
dibangunnya Pelabuhan Cikidang tentunya sudah diperhitungkan mengenai aspek finansial dan manfaat dari pelabuhan tersebut untuk kepentingan nelayan secara khusus dan masyarakat luas pada umumnya. Pembangunan yang tidak melibatkan masyarakat setempat khususnya nelayan akan berakibat fatal terhadap tujuan akhir dari pembangunan tersebut.

Program Community-based Settlement Rehabilitation and Reconstruction Project (CSRPP) atau Proyek Rehabilitasi dan Rekonstruksi Masyarakat dan Permukiman Berbasis Komunitas (REKOMPAK), program ini tentunya melibatkan nelayan secara langsung dalam rehabilitasi fasilitas umum dan perorangan pasca terjadinya tsunami. Tenaga kerja yang dilibatkan dalam rehabilitasi ini diantaranya nelayan sendiri, sehingga pada saat tidak memiliki modal untuk melaut mereka dapat bekerja pada proyek REKOMPAK. Setelah mendapatkan upah ada sebagian yang dipergunakan unutuk biaya operasional melaut.

Kebijakan pemerintah pusat melalui pemerintah daerah seperti Program Nasional Pemberdayaan Masyarakat (PNPM) Mandiri sebagai wadah programprogram pemberdayaan yang tersebar di berbagai instansi yang dikoordinasikan oleh Kementerian Koordinator Bidang Kesejahteraan Rakyat. PNPM Mandiri secara umum bertujuan meningkatkan kesejahteraan dan kesempatan kerja masyarakat miskin secara mandiri. Dalam pelaksanaannya, program ini berjalan dengan menggunakan 2 (dua) prinsip, yaitu (1) enpowerment (pemberdayaan) dan (2) entrepeneurship (kewirausahaan) program ini selain membangun kesadaran masyarakat untuk mandiri dengan memfasilitasi peningkatan kapasitas masyarakat, juga membangun mentalitas masyarakat yang mandiri serta mengurangi ketergantungan pada bantuan-bantuan pemerintah. Program Nasional Pemberdayaan Masyarakat Mandiri Kelautan dan Perikanan (PNPM Mandiri-KP). Selanjutnya pelaksanaan PNPM MandiriKP diharapkan dapat mendukung program penanggulangan kemiskinan yang sedang digalakkan pemerintah utamanya bagi masyarakat kelautan dan perikanan.

Program pemberdayaan Ekonomi Masyarakat Pesisir (PEMP) pada dasarnya untuk mengatasi dampak kenaikan bahan bakar minyak dengan difokuskan pada penguatan modal secara bergulir. Program PEMP ini terdiri dari kegiatan (1) pengembangan lembaga keuangan mikro dengan nama Lembaga Ekonomi Pengembangan Pesisir-Mikro Mitra Mina (LEPP-M3) ; (2) pengembangan usaha ekonomi produktif dan (3) pelatihan dan pengembangan kapasitas kelembagaan masyarakat lokal.

\section{PENGENDALIAN UPAYA PENANGKAPAN}

Pengendalian upaya penangkapan memiliki nilai bobot parsial sebesar 0,336 artinya alternatif kebijakan pemerintah melalui pengendalian upaya penangkapan memiliki pengaruh sebesar 33,6\% terhadap tingkat keberlanjutan pengelolaan sumber daya perikanan.

Tindakan yang bersifat mengendalikan upaya penangkapan adalah yang berorientasi ke depan dengan membatasi jumlah unit penangkapan melalui pembatasan surat ijin yang dikeluarkan, pembatasan jumlah unit waktu penangkapan. Beberapa hal yang perlu diperhatikan dalam pelaksanaan input kontrol antara lain: (1) pembatasan jumlah unit jenis alat penangkapan tertentu; (2) membatasi jumlah upaya penangkapan berarti menggurangi mortalitas penangkapan, pemegang hak untuk masyarakat lokal akan memiliki kecenderungan untuk mengelola sesuai dengan kepentingan ekonominya. Kesulitan terbesar dalam memakai input control untuk mengatur perikanan berkaitan dengan masalah penentuan berapa sebenarnya jumlah upaya masing-masing unit penangkapan yang ada.

Tindakan pengaturan yang bersifat pengendalian hasil tangkapn (output control) adalah membatasi jumlah hasil tangkapan sampai pada tingkat pemanfaatan yang diperbolehkan. Keadaan dilapangan membuktikan bahwa kurangnya pengawasan 
terhadap input dan output sumber daya perikanan tangkap telah menimbulkan terjadinya overfishing, hal ini diperkuat dengan data hasil tangkapan yang cenderung mengalami penurunan selama 11 tahun terakhir.

\section{MEMPERHATIKAN MODEL SINERGITAS PERILAKU EKONOMI NELAYAN}

Memperhatikan sinergitas perilaku ekonomi nelayan memiliki nilai bobot parsial sebesar 0,131 artinya alternatif kebijakan pemerintah dengan memperhatikan sinergitas perilaku ekonomi nelayan memiliki pengaruh sebesar $13,1 \%$ terhadap tingkat keberlanjutan pengelolaan sumber daya perikanan.

Pada hakekatnya pembinaan perilaku ekonomi nelayan dan kelembagaan sosial adalah untuk menggalang partisipasi segenap masyarakat desa dalam program-program pembangunan. Secara sosiologis, partisipasi nelayan ini sangat penting artinya dalam proses pembangunan yang berkelanjutan. Sinergitas antara kebijakan pemerintah dengan nelayan sebagai pelaku utama dalam pembangunan dapat dilihat pada Gambar 1.

Pembangunan wilayah pesisir harus memungkinkan terbukanya peluang bagi nelayan untuk berpartisipasi sebagai subyek dan bukan sebagai obyek semata. Keberhasilan pembangunan yang berkelanjutan akan ditentukan oleh keterlibatan nelayan dengan sumber daya perikanan tangkap. Dalam hubungan ini, partisipasi dapat diartikan sebagai keikutsertaan proporsional dalam sesuatu kegiatan. Partisipasi yang dilakukan oleh komunitas nelayan merupakan kesadaran tentang pentingnya memiliki rasa tanggungjawab untuk memanfaatkan sumberdaya secara optimal dan berkelanjutan.

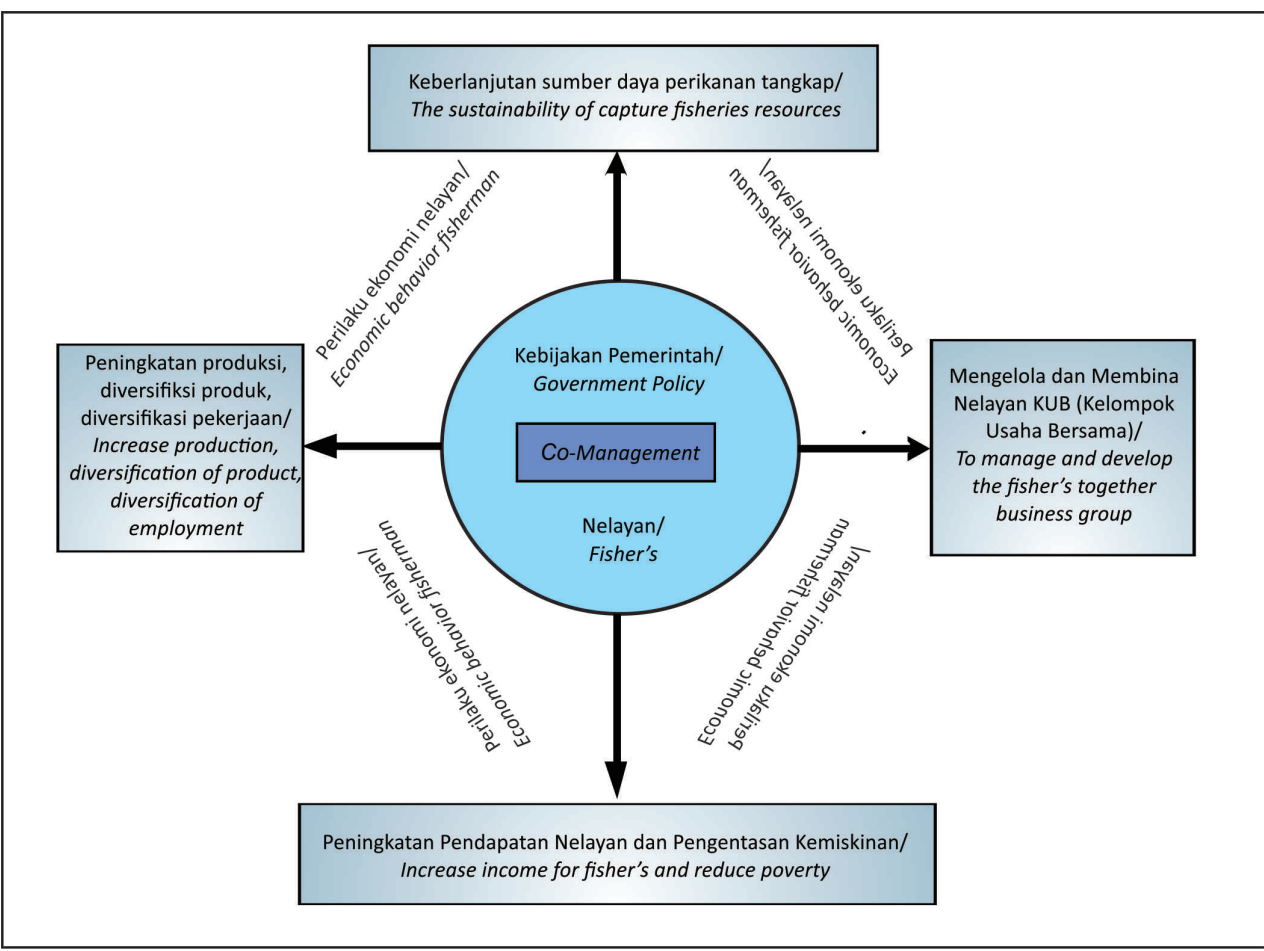

Gambar 1. Model Sinergitas Perilaku Ekonomi Nelayan Terhadap Tingkat Keberlanjutan Sumberdaya Perikanan.

Figure 1. Synergy Models of Economic Behavior Fisher's Toward Level Fisheries Resource Sustainability. 
Pola pembangunan yang top-down, tidak melibatkan masyarakat dalam proses perencanaan dan pengambilan keputusan, mengakibatkan nelayan sebagai obyek pembangunan, sehingga kebanyakan nelayan tidak kreatif dan tidak punya rasa memiliki (sense of ownership) terhadap programprogram pembangunan. Bila dilihat dari aspek sosial ternyata usaha penangkapan ikan secara berkelompok (Kelompok Usaha Bersama) yang melibatkan beberapa nelayan sudah merupakan tradisi di kalangan nelayan itu sendiri. Selain itu kelompok nelayan pemilik motor tempel selama ini telah menunjukkan kerjasama yang serasi, sehingga perbaikan teknologi dan peningkatan modal diperkirakan jangan sampai menimbulkan konflik sosial di antara nelayan setempat, hal inilah yang harus menjadi fokus dari pembinaan pemerintah terhadap nelayan.

Gambar 1 model sinergitas perilaku ekonomi nelayan yang merupakan satu kesatuan yang utuh antara kebijakan pemerintah dengan nelayan sebagai steakholder yang didalamnya ada unsur pengelolaan yang melibatkan komunitas nelayan setempat. Sinergitas kebijakan pemerintah dengan nelayan melalui co-management yang bertujuan untuk: (1) peningkatan produksi, diversifikasi produksi, diversifikasi pekerjaan yang berbanding lurus dengan membina dan mengelola nelayan seperti halnya melalui Kelompok Usaha Bersama (KUB); (2) meningkatkan pendapatan nelayan dan pengentasan kemiskinan yang berbanding lurus dengan keberlanjutan sumber daya perikanan tangkap. Tujuan tersebut dijembatani oleh perilaku ekonomi nelayan baik secara rasional maupun irrasional dalam pengambilan keputusannya.

Kebanyakan kegiatan melaut nelayan di kawasan Pangandaran hanya satu hari (one day fishing). Untuk meningkatkan kualitas SDM nelayan nasional agar kompetitif, perlu diberikan pendidikan, pelatihan dan penyuluhan tentang teknik penangkapan ikan, manajemen keuangan, manajemen lingkungan hidup, dan etos kerja termasuk achievement and motivation secara berkesinambungan.
Misalnya mendidik dan melatih para nelayan kita agar punya keterampilan dan etos kerja.

Kecamatan Parigi salah satunya memiliki Kelompok Usaha Bersama (KUB), hasil tangkapan ikan di laut yang ada kemudian diolah serta didistribusikan kepada konsumen lokal. Di Desa Karangjaladri terdapat 4 KUB yaitu: (1) Mina Jaya; (2) Ayu Pamayang; (3) Marga Mina; (4) Mina Pari. Marga Mina merupakan salah satu KUB yang paling menonjol diantara yang lainnya, hal tersebut dapat terlihat karena prestasi serta manajemen keorganisasian yang sudah mumpuni dan memiliki anggota sebanyak 28 orang yang tersebar tidak hanya di dusun Bojongsalawe.

\section{PENEGAKAN HUKUM}

Penegakan hukum dan kelembagaan memiliki nilai bobot parsial sebesar 0,088 artinya setiap kebijakan pemerintah melalui penegakan hukum dan kelembagaan memiliki pengaruh sebesar 0,92\% terhadap tingkat keberlanjutan pengelolaan sumber daya perikanan.

Nelayan dalam melakukan usahanya tentunya menginginkan untuk mengikuti peraturan yang telah diberlakukan oleh pemerintah daerah dan pusat, seperti penggunaan alat tangkap ikan jenis bagan, berdasarkan wawancara dengan aparat daerah mereka tidak bisa memungkiri keberadaan bagan dan tindakan tegas dari pihak pemerintah pun tidak bisa diterapkan dengan alasan kondisi nelayan yang semakin terpuruk dari hasil tangkapan yang cenderung menurut dan menimbulkan gejolak di masyarakat karena pemilik bagan itu memiliki kekuasaan yang besar yang bisa mempengaruhi masyarakat sekitar.

Sudut pandang yang seperti itu memperlihatkan ketidakberanian pemerintah dalam menerapkan peraturan, padahal seharusnya pemerintah melakukan sosialisasi, penyuluhan secara bertahap akan mampu mengubah perilaku nelayan yang kurang baik menjadi lebih baik. Kedekatan antara 
pemerintah daerah dengan masyarakatnya akan terlihat dari hasil program secara berkesinambungan. Partisipasi aktif komunitas nelayan dalam melakukan pengelolaan pengaturan sumber daya perikanan bertujuan untuk meningkatkan kesadaran masyarakat terhadap pentingnya konservasi sumber daya ikan.

Pengelolaan sumber daya perikanan dengan melakukan pengendalian upaya penangkapan (input control) tindakan ini berorientasi untuk jangka panjang dengan membatasi jumlah unit penangkapan melalui pembatasan surat ijin yang dikeluarkan serta pembatasan penggunaan kapal dan alat tangkap. Dengan membatasi jumlah upaya penangkapan berarti menggurangi mortalitas penangkapan. Pengendalian hasil tangkapan (output control) membatasi jumlah hasil tangkapan sampai pada tingkat pemanfaatan yang diperbolehkan.

\section{PENUTUP}

Berdasarkan Analytical Hierarkhi Process (AHP) kebijakan pemerintah daerah dalam mendukung tingkat keberlanjutan sumber daya perikanan dengan meningkatkan pembinaan Kelompok Usaha Bersama (KUB) nelayan, penegakan hukum dalam mendukung keberlanjutan pengelolaan sumber daya perikanan, penyelesaian Pelabuhan Penangkapan Ikan (PPI) Cikidang dan bantuan modal bergulir bagi nelayan. Kebijakan pemerintah daerah dalam mendukung keberlanjutan sumber daya perikanan tangkap harus dilakukan melalui sosialisasi secara bertahap dengan dukungan model pengelolaan partisipasi komunitas nelayan lokal, sehingga memberikan rasa tanggungjawab bagi nelayan itu sendiri.

\section{DAFTAR PUSTAKA}

Bengen, D.G. 2005. Merajut Keterpaduan Pengelolaan Sumberdaya Pesisir dan Laut Kawasan Timur Indonesia Bagi Pembangunan Kelautan Berkelanjutan. Disajikan pada Seminar Makassar Maritime Meeting. Makasar.
Berkes, F., R. Mahon, P. McConney, R. Pollnac and R. Pomeroy. 2001. Managing smallscale fisheries: alternative directions and methods. International Development Research Centre, Canada. 320pp.

Brown, D.N. and R.S. Pomeroy. 1999. Co-management of Caribbean community (CARICOM) fisheries. Marine Policy. 23(1): 549-570.

Dinas Kelautan dan Perikanan Kabupaten Ciamis. 2007. Laporan Tahunan Dinas Kelautan dan Perikanan Kabupaten Ciamis Tahun 2007. Dinas Kelautan dan Perikanan Kabupaten Ciamis. Ciamis.

Dinas Kelautan dan Perikanan Propinsi Jawa Barat. 1999-2010. Statistik Perikanan Propinsi Jawa Barat Tahun 1999-2010. Dinas Kelautan dan Perikanan Propinsi Jawa Barat. Bandung.

Edward H.A., F. Ellis. 2001. The livelihoods approch and management of small-scale fisheries. Received 10 June 2001; received in revised from 26 July 2001; accepted 26 July 2001. Marine Policy 25 (2001) 3773888 www.elseiver.com/loceted/marpol. Akses tgl 28 Oktober 2009.

Fauzi, A. dan S. Anna. 2005. Pendekatan Sumberdaya Perikanan dan Kelautan Untuk Analisis Kebijakan. PT.Gramedia Pustaka Utama. Jakarta.

Lackey,R. T. 1998. Fisheries management : integrating societal preference decesion analysis and ecological risk assssmnet. Environmental Science and Policy. 1(4) : 329-335.

Matsuda, H., M. Makino and Y. Sakurai. 2009. Development of an adaptive marine ecosystem management and comanagement plan at the Shiretoko World Natural Heritage Site. (www.elsiver.com/ located/biocon. 21 April 2009, diakses tanggal 28 Oktober 2009).

McConney, P., and R. Baldeo.2007. Lessons in comanagement from beach seine and lobster fisheries in Grenada. Fisheries Research 87. 77-85 www.elsevier .com/located/ fisheries. Akses tgl 28 Oktober 2009. 
Mohottala, G.K., U.S. Amarasinghe, P. Wattage and S. S. De Silvia. 2009. Evaluations of Community Participation For The Development Of Culture - Based Fisheries In Village Reservoirs of Srilangka. Aquaculture Economic \& Management,13:22-38,2009. Copyright 2009 IAAEM ISSN.

Nazir, M. 2003. Metode Penelitian. PT. Ghalia Indonesia.

Pomeroy R., and L. Garces, M. Pido, G. Silvestre. 2009. Ecosystem based fisheries management in small - scale tropical marine fisheries: Emerging model of governanance arrangement in the Philippines. Marine Policy 34 (2010) 298308A. Article history: journal homepage: www.elsevier.com/located/fisheries. Accepted 25 July 2009. Akses tgl 28 Oktober 2009.
Pomeroy, R. 1995. Community-based and comanagement institutions for sustainable coastal fisheries management in Southeast Asia. Ocean and Coastal Management. 27 (33). Pp. 143-162.

Saaty TL. 1993. Pengambilan Keputusan Bagi Para Pemimpin (Proses Hierarki Analitik untuk Pengambilan Keputusan dalam Situasi yang Kompleks). P.T. Pustaka Binaman Pressindo. Jakarta (Terjemahan). Jakarta.

Triantaphyllou, E., and S. Alfonso. 1997. A Sensitivity Analysis Approach For Some Deterministic Multi-Criteria Decision Making Methods. Decision Sciences. 28(1). pp 151-194. 